\title{
A clinical review of reconstructive techniques for patients with multiple skin cancers on the face
}

\author{
Geon Woo Kim ${ }^{1}$, \\ Yong Chan $\mathrm{Bae}^{1,2}$, \\ Sung Hwan Bae', \\ Su Bong Nam ${ }^{1}$, \\ Dong Min Lee ${ }^{1}$ \\ ${ }^{1}$ Department of Plastic and \\ Reconstructive Surgery, Pusan National \\ University School of Medicine, Busan; \\ ${ }^{2}$ Biomedical Research Institute, Pusan \\ National University Hospital, Busan, \\ Korea
}

\begin{abstract}
Background: Cases of simultaneous multiple skin cancers in a single patient have become more common. Due to the multiplicity of lesions, reconstruction in such cases is more difficult than after a single lesion is removed. This study presents a series of patients with multiple facial skin cancers, with an analysis of the surgical removal, reconstruction process, and the results observed during follow-up.

Methods: We reviewed 12 patients diagnosed with multiple skin cancers on the face between November 2004 and March 2016. The patients' medical records were retrospectively reviewed to identify the type of skin cancer, the site of onset, methods of surgical removal and reconstruction, complications, and recurrence during follow-up.

Results: Nine patients had a single type of cancer occurring as multiple lesions, while three patients had different skin cancer types that occurred together. A total of 30 cancer sites were observed in the 12 patients. The most common cancer site was the nose. Thirteen defects were reconstructed with a flap, while 18 were reconstructed with skin grafting. The only complication was one case of recurrence of basal cell carcinoma.

Conclusion: Multiple skin cancers are removed by performing Mohs micrographic surgery or wide excision, resulting in multiple defect sites. The authors emphasize the importance of thoroughly evaluating local lesions surrounding the initially-identified lesions or on other sites when reconstructing a large defect which can not be covered by primary closure. Furthermore, satisfactory results can be obtained by using various methods simultaneously regarding the condition of individual patients, the defect site and size, and the surgeon's preference.
\end{abstract}

Keywords: Skin neoplasms / Melanoma / Basal cell carcinoma / Mohs surgery

\section{INTRODUCTION}

Case reports of multiple skin cancers occurring simultaneously in a single patient have become more common [1-3]. Previous studies of multiple skin cancer patients have described cases occurring after organ transplantation, hematopoietic cell transplant in patients with lymphocytic leukemia, or immunosup-

Correspondence: Yong Chan Bae

Department of Plastic and Reconstructive Surgery, Pusan National University School of Medicine and Biomedical Research Institute, Pusan National University Hospital, 179 Gudeok-ro, Seo-gu, Busan 49241, Korea

E-mail: baeyc2@hanmail.net

Received July 12, 2018 / Revised September 5, 2018 / Accepted September 18, 2018 pressive therapy to treat Behcet disease [1,4]. Multiple skin cancers may also occur with prolonged ultraviolet light therapy to treat Netherton syndrome, and studies have also reported incidental occurrences in other circumstances. Multiple lesions have been reported to occur more often in basal cell carcinoma than in other skin cancers, and therefore more studies have reported the histopathological characteristics and risk factors of multiple basal cell carcinoma [5].

A problem facing clinicians is that when multiple lesions are detected at the same time, multiple lesions must be surgically removed, making reconstruction more difficult than after a single lesion is removed. If the defect site after skin cancer re- 
moval is small, it can be covered using simple primary closure. However, if the defect site is large, a range of well-known reconstructive methods can be used, such as split-thickness skin grafting, full-thickness skin grafting, and various local flaps, and when necessary, skin grafting and local flaps can be used together.

According to previous studies, cases of multiple skin cancers are extremely rare, and thus, no studies have reported the techniques used to reconstruct the multiple defect sites that occur after multiple skin cancer removal. This study presents a series of patients with multiple facial skin cancers, with an analysis of the surgical removal and reconstruction process and the results observed during follow-up.

\section{METHODS}

The 12 subjects of this study were patients diagnosed with multiple skin cancers on the face between November 2004 and March 2016. Cases that could be reconstructed with primary closure after skin cancer excision were excluded from the study. For each case, the following parameters were analyzed: the type of skin cancer, the type and site of skin cancer, methods for surgical removal and reconstruction, complications, and recurrence during follow-up. All data were collected from the patients' operative charts and medical records during the period of follow-up observations. The follow-up period was an average of 36 months, ranging from 2 years to 6 years after surgery. Of the 12 patients, eight were male and four were female, and their average age was 64 years (range, 43 to 87 years).

\section{RESULTS}

Nine patients had a single type of cancer, such as basal cell carcinoma or squamous cell carcinoma, occurring as multiple lesions, while three patients had different skin cancer types that occurred together. There was one case of squamous cell carcinoma and malignant melanoma that occurred together and two cases of squamous cell carcinoma and basal cell carcinoma that occurred together.

A total of 30 cancer sites were observed in the 12 patients. The nose was the most common cancer site, with 10 tumors, followed by the forehead (five tumors), the periorbital region (four tumors), the temple (four tumors), the cheek (four tumors), the scalp (two tumors), and the lip (one tumor) (Table 1). According to the excision method, eight cases were reconstructed after Mohs microsurgery, and four cases were reconstructed after wide excision (Table 2).

The 30 defects were reconstructed using 31 techniques, as
Table 1. Tumor sites in 12 patients with skin cancer on the head and neck

\begin{tabular}{lc}
\hline Cancer site & Number \\
\hline Nose & 10 \\
Forehead & 5 \\
Periorbital region & 4 \\
Temple & 4 \\
Cheek & 4 \\
Scalp & 2 \\
Lip & 1 \\
Total & 30 \\
\hline
\end{tabular}

there were cases in which multiple techniques were used on a single site due to its size. Reconstruction with a flap was conducted 13 times, while skin grafting was performed 18 times (12 split-thickness skin grafts and six full-thickness grafts). For reconstruction, a simple advancement flap was used six times, a forehead flap two times, a pivot flap two times, a V-Y advancement flap one time, and the Webster modification of the Bernard technique one time.

There were no cases of flap necrosis or any cases of infection or necrosis after the skin graft. Other than one case of recurrence of basal cell carcinoma, no other complications occurred.

\section{Case 1}

The patient in case 1 was a 75-year-old man who noticed multiple black papules on his face 2 years prior to visiting the Pusan National University Hospital (Fig. 1A). Biopsy revealed basal cell carcinoma in the glabella, lower eyelid, and nasal side wall. Dermatologists at the hospital performed Mohs micrographic surgery under local anesthesia, and negative margins were verified. Based on the size and site of the defects, it was determined that all the defects should be reconstructed with a full-thickness graft (Fig. 1B). Full-thickness skin was harvested from the left retroauricular region and grafted. The patient is receiving outpatient follow-up and has not shown any other abnormal findings, such as recurrence or eyelid deformity due to contracture, as of 18 months postoperatively (Fig. 1C). There were black papules located on sites other than the surgical site that could have been cancerous. They were biopsied and diagnosed as seborrheic keratosis, and were therefore excluded from surgery.

\section{Case 2}

The patient in case 2 was a 43 -year-old man who noticed black nodules on his left suprabrow region and lower eyelid 3 years prior to visiting the hospital's dermatology department (Fig. 2A). Biopsy indicated basal cell carcinoma. After conducting Mohs micrographic surgery (Fig. 2B), a median forehead island flap was used to reconstruct the defect that remained after exci- 
Table 2. Patients' information

\begin{tabular}{|c|c|c|c|c|c|}
\hline Case no. & Sex & Age (yr) & Etiology and location & Excision method & Reconstructive technique \\
\hline 1 & M & 67 & $\begin{array}{l}\text { Squamous cell carcinoma on } \\
\text { (1) parietal region, Rt } \\
\text { (2) temple region, Rt }\end{array}$ & Wide excision & $\begin{array}{l}\text { (1) Scalp rotation flap and temporalis muscle } \\
\text { advancement flap with mesh skin graft } \\
\text { (2) Mesh skin graft }\end{array}$ \\
\hline 2 & M & 48 & $\begin{array}{l}\text { Basal cell carcinoma on } \\
\text { (1) scalp } \\
\text { (2) forehead } \\
\text { (3) temple region, Rt } \\
\text { (4) cheek, Rt }\end{array}$ & Wide excision & $\begin{array}{l}\text { (1) Medium split-thickness skin graft } \\
\text { (2) Simple advancement flap } \\
\text { (3) Simple advancement flap } \\
\text { (4) Simple advancement flap }\end{array}$ \\
\hline 3 & M & 72 & $\begin{array}{l}\text { Basal cell carcinoma on } \\
\text { (1) medial canthal region, Lt } \\
\text { (2) nasal alar region, Rt }\end{array}$ & Mohs surgery & $\begin{array}{l}\text { (1) Simple advancement flap } \\
\text { (2) Nasolabial V-Y advancement flap }\end{array}$ \\
\hline 4 & M & 56 & $\begin{array}{l}\text { Basal cell carcinoma on } \\
\text { (1) forehead } \\
\text { (2) medial side of eyebrow region, Rt }\end{array}$ & Mohs surgery & $\begin{array}{l}\text { (1) Full-thickness skin graft } \\
\text { (2) Full-thickness skin graft }\end{array}$ \\
\hline 5 & $\mathrm{~F}$ & 68 & $\begin{array}{l}\text { Basal cell carcinoma on } \\
\text { (1) nasal tip } \\
\text { (2) nasal dorsum } \\
\text { (3) alar region, Rt }\end{array}$ & Wide excision & $\begin{array}{l}\text { (1) Medium split-thickness skin graft } \\
\text { (2) Medium split-thickness skin graft } \\
\text { (3) Medium split-thickness skin graft }\end{array}$ \\
\hline 6 & $F$ & 83 & $\begin{array}{l}\text { Squamous cell carcinoma on } \\
\text { (1) temple region, Rt } \\
\text { Basal cell carcinoma on } \\
\text { (2) cheek, Rt } \\
\text { (3) nasal alar region, Lt }\end{array}$ & Wide excision & $\begin{array}{l}\text { (1) Medium split-thickness skin graft } \\
\text { (2) Medium split-thickness skin graft } \\
\text { (3) Simple advancement flap }\end{array}$ \\
\hline 7 & $\mathrm{~F}$ & 71 & $\begin{array}{l}\text { Basal cell carcinoma on } \\
\text { (1) nasal dorsum } \\
\text { (2) nasal vestibular region, Rt }\end{array}$ & Mohs surgery & $\begin{array}{l}\text { (1) Medium split-thickness skin graft } \\
\text { (2) Medium split-thickness skin graft }\end{array}$ \\
\hline 8 & M & 49 & $\begin{array}{l}\text { Basal cell carcinoma on } \\
\text { (1) forehead } \\
\text { (2) nasal side wall, Rt }\end{array}$ & Mohs surgery & $\begin{array}{l}\text { Mohs surgery and reconstruction by } \\
\text { (1) simple advancement flap } \\
\text { (2) median forehead flap }\end{array}$ \\
\hline 9 & M & 43 & $\begin{array}{l}\text { Basal cell carcinoma on } \\
\text { (1) suprabrow region, Lt } \\
\text { (2) lower eyelid, Lt }\end{array}$ & Mohs surgery & $\begin{array}{l}\text { Mohs surgery and reconstruction by } \\
\text { (1) median forehead island flap } \\
\text { (2) musculocutaneous switch flap }\end{array}$ \\
\hline 10 & $\mathrm{~F}$ & 82 & $\begin{array}{l}\text { (1) Squamous cell carcinoma on lower lip } \\
\text { (2) Basal cell carcinoma on nasolabial fold, Lt }\end{array}$ & $\begin{array}{l}\text { (1) Wide excision } \\
\text { (2) Mohs surgery }\end{array}$ & $\begin{array}{l}\text { (1) Webster modification of Bernard technique, Lt } \\
\text { (2) Full-thickness skin graft }\end{array}$ \\
\hline 11 & M & 75 & $\begin{array}{l}\text { (1) Malignant melanoma on temple region, Lt } \\
\text { (2) Squamous cell carcinoma on cheek, Rt } \\
\text { (3) Squamous cell carcinoma on forehead }\end{array}$ & $\begin{array}{l}\text { (1) Wide excision } \\
\text { (2) Mohs surgery }\end{array}$ & $\begin{array}{l}\text { (1) Medium split-thickness skin graft } \\
\text { (2) Medium split-thickness skin graft } \\
\text { (3) Medium split-thickness skin graft }\end{array}$ \\
\hline 12 & M & 75 & $\begin{array}{l}\text { Basal cell carcinoma on } \\
\text { (1) glabella } \\
\text { (2) nasal side wall, Lt } \\
\text { (3) lower eyelid, Lt }\end{array}$ & Mohs surgery & $\begin{array}{l}\text { (1) Full-thickness skin graft } \\
\text { (2) Full-thickness skin graft } \\
\text { (3) Full-thickness skin graft }\end{array}$ \\
\hline
\end{tabular}

M, male; F, female; Rt, right; Lt, left.

sion of the lesion on the suprabrow region. The tarsal plate and conjunctiva were repaired to reduce the size of the defect after wedge excision was performed on the lower eyelid. A bipedicled orbicularis ocull musculocutaneous flap was used starting in the superior area of the upper eyelid. Two weeks after surgery, division and insetting of the eyelid flap were performed. The patient was observed for recurrence or eyelid deformity through outpatient follow-up. Fig. $2 \mathrm{C}$ is an image of the surgi- cal area taken 5 years after surgery. The patient did not express discomfort or other complaints and was satisfied with the results of surgery.

\section{Case 3}

The patient in case 3 was an 82-year-old woman who reported that a black macule appeared on her left nasolabial fold 4 years before visiting the hospital and that a black ulcer-like lesion ap- 

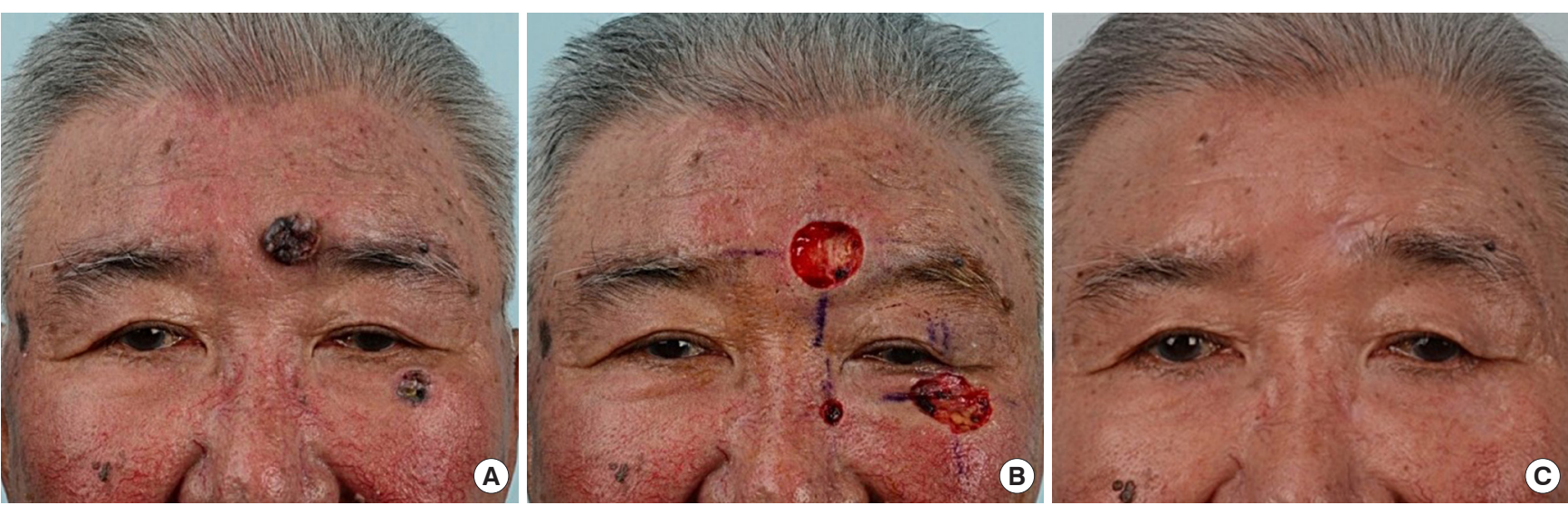

Fig. 1. A 75-year-old male patient with basal cell carcinoma on the glabella, left nasal side wall, and left lower eyelid. (A) Before Mohs micrographic surgery. (B) After Mohs micrographic surgery. (C) Postoperative photo obtained 1.5 years after reconstruction (full-thickness skin graft).
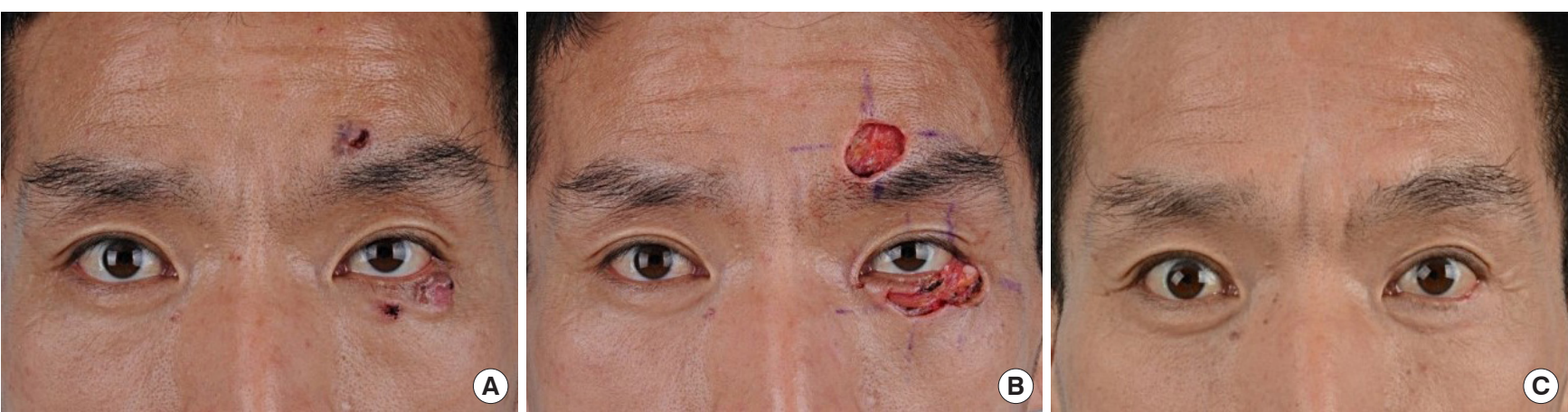

Fig. 2. A 43-year-old male patient with basal cell carcinoma on the left suprabrow region and left lower eyelid. (A) Before Mohs micrographic surgery. (B) After Mohs micrographic surgery. (C) Postoperative photo obtained 5 years after reconstruction (suprabrow, median forehead island flap; lower eyelid, orbicularis ocull musculocutaneous flap).
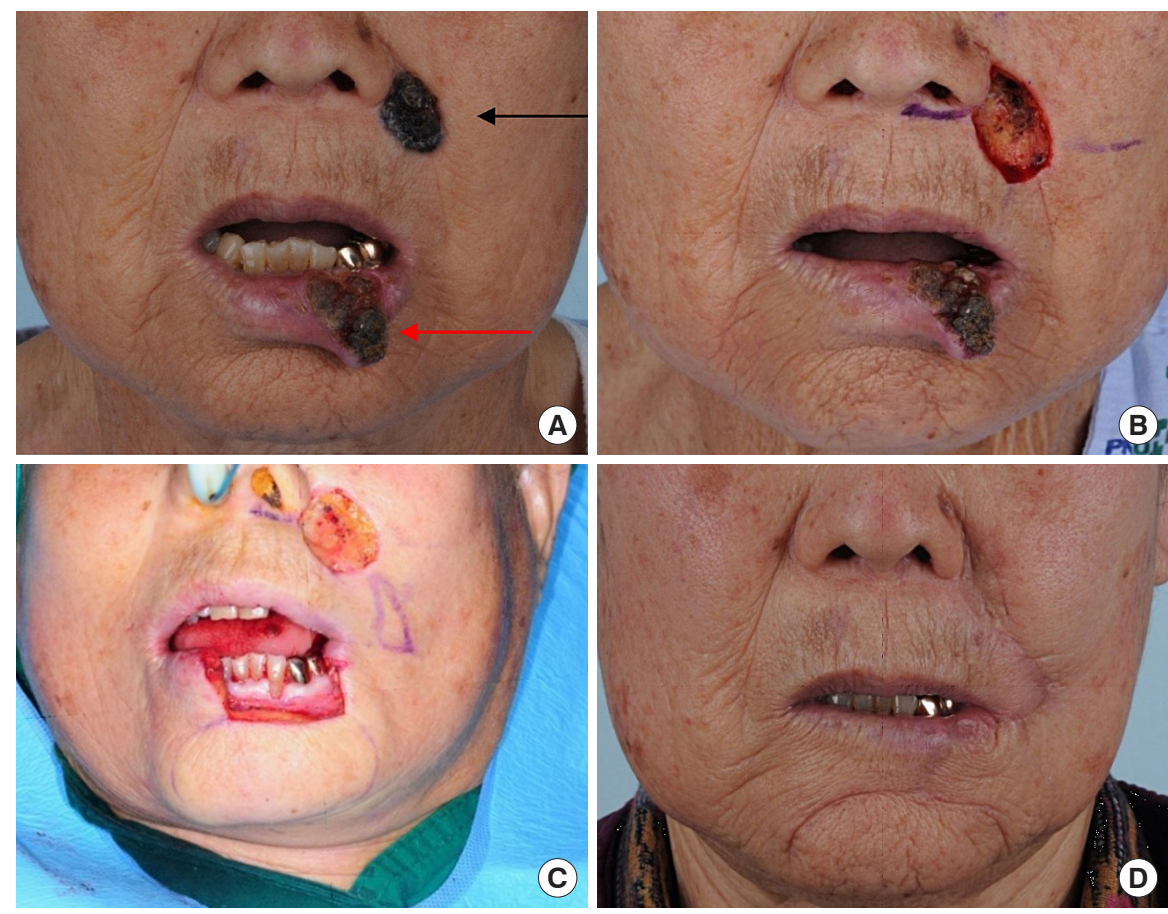

Fig. 3. An 82-year-old female patient with basal cell carcinoma on the left nasolabial fold and squamous cell carcinoma on the lower lip. (A) Before Mohs micrographic surgery. Black arrow indicates basal cell carcinoma and red arrow indicates squamous cell carcinoma. (B) After Mohs micrographic surgery. (C) After wide excision. (D) Postoperative photo obtained 6 months after reconstruction (nasolabial fold, full-thickness skin graft; lower lip, Webster modification of the Bernard technique). 
peared on her lower lip 3 years prior to visiting the hospital (Fig. 3A). Biopsy indicated basal cell carcinoma on the left nasolabial fold and squamous cell carcinoma on the lower lip. As a special case in which both basal cell carcinoma and squamous cell carcinoma were present, Mohs micrographic surgery was performed under local anesthesia for the basal cell carcinoma and wide excision was performed under general anesthesia for the squamous cell carcinoma on the lower lip (Fig. 3B, C). The Webster modification of the Bernard technique was used on the left side, and advancement was performed through a barrelshaped incision made on the lower right side for lower lip reconstruction. Both sides of the nasolabial fold were dissected above the muscle layer to reduce the size of the defect through maximal approximation to the subcutaneous level. Excision using the Webster modification of the Bernard technique was performed, and the remaining skin was defatted to perform a full-thickness skin graft. Fig. 3D is a follow-up image of the surgical area 6 months after surgery.

\section{DISCUSSION}

Most studies regarding multiple skin cancers occurring on multiple sites in a single patient have focused on basal cell carcinoma, and little research has been conducted on cases of other multiple skin cancers. This is most likely due to the fact that the prevalence of basal cell carcinoma is higher than that of other skin cancer types [3]. Multiple basal cell carcinomas are known to occur on exposed skin areas fairly often in Caucasians living near the equator. Based on the results of studies conducted in European countries, $30 \%$ of basal cell carcinomas are multiple $[5,6]$. Studies on multiple basal cell carcinomas are still lacking in Korea, but such studies should be conducted because this condition has become more common.

As for multiple skin cancers other than basal cell carcinoma, a report described multiple squamous cell carcinomas that occurred from hydroxyurea treatment on a patient with a hematologic disorder [7]. Multiple skin cancers are removed by performing Mohs micrographic surgery or by performing wide excision to remove a large area, which results in multiple defect sites. In these cases, a range of reconstructive procedures, such as skin grafts and local flaps, can be considered for the simultaneous reconstruction of wide defect sites that are impossible to reconstruct with primary closure. Based on our years of experience with various patients, the authors were able both to reduce the burden faced by patients and to achieve satisfactory aesthetic outcomes by applying the most appropriate reconstructive techniques in each case.

Through this study, the authors attempted to raise awareness of the need to thoroughly evaluate local lesions surrounding the lesions or on other sites when treating patients with skin cancer. Furthermore, this study sought to provide useful information for the decision-making process regarding reconstruction in skin cancer patients with multiple defect sites by investigating cases of multiple skin cancers that have not been reported previously and by analyzing the appropriate reconstructive methods for such cases.

In the case of multiple skin cancer, sufficient consideration should be required for the site and size of the cancer in comparison to skin cancer in a single site. It is difficult to talk generally about reconstruction methods according to site and size, but if there are two or more defects, there is a limitation in the reconstruction method. In case 12 of our study, if cancer was present alone in the lower eyelid, we could have used a orbicularis oculi myocutaneous flap with full-thickness skin graft to achieve aesthetically better results. However, due to defect of nasal side wall, orbicularis oculi myocutaneous flap was limited and reconstructed by full-thickness skin graft alone.

Especially, if different types of skin cancer occur in multiple site, it should be removed according to each type of cancer treatment, but the possibility of recurrence and damage of critical structures below it must be fully considered. That's the case with 10 and 11. In particular, the 11th patient had relatively large defect size in the temple region where malignant melanoma occurred. However, in order to follow up the recurrence, we performed split-thickness skin graft without any other local flap or free flap. Finally, we were able to reconstruct without any recurrence.

The authors performed various reconstruction methods coming from experience that best meet the needs of the 12 patients with multiple skin cancers based on the site and size of the defect sites that occurred after tumor removal. All patients experienced satisfactory results without any complications. The main limitation of this study, however, is that the number of patients in this study was not large enough to conduct a statistical analysis.

The proper choice of reconstructive method depends largely on the patient's condition, the defect site, and the surgeon's preference. The authors expect that this study will be helpful to patients with multiple defect sites on the face through our findings regarding the various methods of reconstruction analyzed in this study.

\section{CONFLICT OF INTEREST}

No potential conflict of interest relevant to this article was reported. 


\section{PATIENT CONSENT}

The patients provided written informed consent for the publication and the use of their images.

\section{REFERENCES}

1. Kim MS, Kim YS, Na CH, Shin BS. A clinical study of multiple non-melanoma skin cancers over 4 years in a single institution center. Korean J Dermatol 2017;55:165-70.

2. Pereira S, Curado MP, Ribeiro AM. Multiple skin neoplasms in subjects under 40 years of age in Goiania, Brazil. Rev Saude Publica 2015;49:64.

3. Saini R, Sharma N, Pandey K, Puri KJ. Multiple skin cancers in a single patient: multiple pigmented Bowen's disease, giant basal cell carcinoma, squamous cell carcinoma. J Cancer Res Ther 2015;11:669.

4. Sommers SC, Mcmanus RG. Multiple arsenical cancers of skin and internal organs. Cancer 1953;6:347-59.

5. Lee HJ, Kim JM, Kim GW, Ko HC, Kim BS, Kim MB, et al. Clinicohistopathological study of multiple basal cell carcinomas: a single-center study. Korean J Dermatol 2016;54:350-4.

6. Kiiski V, de Vries E, Flohil SC, Bijl MJ, Hofman A, Stricker BH, et al. Risk factors for single and multiple basal cell carcinomas. Arch Dermatol 2010;146:848-55.

7. Kaur J, Sharma N, Sharma S. Multiple cutaneous squamous cell carcinomas: primary carcinomas versus cutaneous metastasis. J Cancer Res Ther 2012;8:300-2. 